\title{
HUBUNGAN PELAKSANAAN IMD DAN PEMBERIAN ASI EKSKLUSIF DENGAN STATUS GIZI BAYI DI DESA BANTARAGUNG KECAMATAN SINDANGWANGI KABUPATEN MAJALENGKA
}

\author{
Eva Fauziah, Ratiah \\ STIKes Kuningan \\ evafauziah.kampus2stikku@gmail.com
}

\begin{abstract}
Abstrak
Keberhasilan pemberian ASI secara eksklusif diawali dengan pelaksanaan inisiasi menyusu dini (IMD), yang dapat mengurangi risiko terhadap kematian pada bayi. Hal ini dikarenakan kandungan di dalam ASI sangat untuk bayi dan juga menjamin status gizi bayi lebih baik dengan adanya faktor protektif dan nutrisi dalam ASI. Namun, saat ini masih ditemukan orang tua yang tidak melaksanakan IMD dan memberikan ASI saja selama 0-6 bulan. Tujuan penelitian ini untuk mengetahui hubungan pelaksanaan IMD dan pemberian ASI Eksklusif dengan status gizi bayi di Desa Bantaragung Kecamatan Sindangwangi Kabupaten Majalengka Tahun 2021.

Penelitian ini menggunakan analitik dengan desain cross sectional. Penelitian dilakukan di Desa Bantaragung Kecamatan Sindangwangi Kabupaten Majalengka sebanyak 40 responden dengan teknik sampling yaitu total sampling. Pengumpulan datanya menggunakan kuesioner, timbangan dan tabel WHO-NCHS. Analisis dalam penelitian ini menggunakan Rank Spearman.

Hasil penelitian ini menunjukkan bahwa sebagian besar bayi di Desa Bantaragung Kecamatan Sindangwangi Kabupaten Majalengka tahun 2021 adalah gizi baik sebesar (65\%). Kurang dari setengah bayi tidak mendapatkan IMD (42,5\%). Kurang dari setengah bayi tidak diberi ASI secara eksklusif (45,0\%). Terdapat hubungan pelaksanaan IMD terhadap status gizi bayi dengan nilai p-value sebesar 0,007. Terdapat hubungan pemberian ASI Eksklusif dengan status gizi bayi dengan nilai $p$-value sebesar 0,040 .

Disarankan pada ibu untuk meningkatkan pengetahuan tentang IMD dan ASI Eksklusif dengan cara berkonsultasi kepada petugas kesehatan, membaca buku KIA dan majalah kesehatan dan bagi bidan desa agar dapat meningkatkan pelayanan kesehatan dengan sering mengadakan penyuluhan sehingga upaya meningkatkan status gizi bayi tercapai.
\end{abstract}


JOURNAL OF PUBLIC HEALTH INOVATION,

VOL. 1 NO. 02, JUNI 2021

DOI: $10.34305 /$ iphi.v1i2.282
Ciptaan disebarluaskan di bawah

Lisensi Creative Commons Atribusi-

NonKomersial-BerbagiSerupa 4.0

Internasional.

Kata kunci: Pelaksanaan IMD, ASI Eksklusif, Status Gizi Bayi

\section{Pendahuluan}

Pembangunan kesehatan setiap negara bertujuan untuk mencetak generasi sumber daya manusia (SDM) di masa depan yang sehat, berkualitas dan mampu bersaing. Pembangunan kesehatan di mulai sejak bayi dikandung ibu kemudian dilahirkan serta mendapatkan nutrisi yang tepat bagi pertumbuhan dan perkembangannya. Nutrisi yang tepat akan membangun dan mencerdaskan generasi. Maka dari itu, pemberian ASI yang diawali ketika inisiasi menyusu dini (IMD) secara, yang dapat mengurangi risiko terhadap kematian pada bayi. Hal ini dikarenakan kandungan di dalam ASI sangat untuk bayi dan juga menjamin status gizi bayi lebih baik dengan adanya faktor protektif dan nutrisi dalam ASI (Ali, 2019).

Menurut hasil Riset Kesehatan Dasar (Riskesdas) tahun 2018 bahwa gizi buruk di Indonesia pada balita usia 0-23 bulan adalah $3,8 \%$, sementara persentase gizi kurangnya adalah $11,4 \%$. Hal tersebut hampir sama dengan hasil dari Pemantauan Status Gizi (PSG) pada tahun 2017, yaitu gizi buruk pada anak usia 0-23 bulan adalah $3,5 \%$ dan gizi kurang adalah 11,3\%.
Adapun provinsi di Indonesia dengan gizi buruk dan gizi kurang pada anak usia 0-23 bulan paling tinggi pada tahun 2018 terdapat di Provinsi Nusa Tenggara Timur sementara yang terendah terdapat di Provinsi Jawa Barat (Kementerian Kesehatan RI, 2020).

Persentase gizi buruk dan gizi kurang pada anak usia 0-23 bulan tahun 2018 di Provinsi Jawa Barat yaitu persentase gizi buruknya sebesar $2,50 \%$ dan persentase gizi kurang sebesar $8,10 \%$ (Kementerian Kesehatan RI, 2020). Meskipun gizi pada bayi di Provinsi Jawa Barat ini terendah, namun hal ini tetap menjadi perhatian karena anak yang mengalami gangguan gizi dapat menyebabkan pertumbuhan jasmani dan kecerdasan anak menjadi tidak normal atau terganggu. Olah karenanya, masalah gizi merupakan masalah bersama dan semua pihak perlu terlibat dalam upaya meningkatkan gizi anak (Ali, 2019).

Terjadinya rawan gizi pada bayi disebabkan antara lain oleh bayi tidak mendapatkan ASI pada jam pertama (Inisiasi Menyusu Dini atau IMD) dan ibu banyak yang mengganti ASI (Air Susu Ibu) 
JOURNAL OF PUBLIC HEALTH INOVATION,

VOL. 1 NO. 02, JUNI 2021

DOI: $10.34305 /$ jphi.v1i2.282

dengan susu formula. ASI bagi anak adalah makanan yang tepat, bergizi, mudah dicerna, dan diserap oleh bayi. Sekitar $80 \%$ dari jumlah ibu, ternyata mampu untuk menghasilkan produksi ASI dalam jumlah yang cukup. ASI sangat baik dan sangat diperlukan oleh bayi tanpa makanan tambahan sampai usia 6 bulan. Ibu dengan gizi kurang juga dapat memproduksi ASI secara cukup tanpa makanan tambahan terutama di usia bayi 0-6 bulan (Parti, 2018).

Pada tahun 2019, secara nasional persentase bayi baru lahir yang mendapat IMD yaitu sebesar 75,58\%. Pelaksanaan IMD pada bayi baru lahir di Provinsi Jawa Barat sebesar 78,81\% dan pencapaian ASI Eksklusif sebesar 63,53\% (Kementerian Kesehatan RI, 2020). Meskipun sudah mencapai dan melebih target Renstra tahun 2019 yaitu sebesar 50,0\%, namun masih perlu ditingkatkan karena masih banyak bayi yang belum mendapatkan IMD dan ASI eksklusif. IMD dan ASI eksklusif merupakan faktor penting terhadap gizi bayi (Roesli, 2019).

Berdasarkan data Dinas Kesehatan Kabupaten Majalengka, jumlah bayi yang mendapat ASI eksklusif 0-6 bulan di Kabupaten Majalengka tahun 2019 sebanyak 15.367 bayi $(73,85 \%)$ dari jumlah
Ciptaan disebarluaskan di bawah Lisensi Creative Commons AtribusiNonKomersial-BerbagiSerupa 4.0

Internasional. keseluruhan sebanyak 20. 835 bayi. Sedangkan Kecamatan Sindangwangi cakupannya ASI eksklusif masih rendah yaitu 443 anak (49,7\%) dari 891 anak (Dinas Kesehatan Kabupaten Majalengka, 2020).

Ketidakberhasilan ibu melakukan IMD, berdampak pada terhambatnya proses pemberian ASI berikutnya. IMD merupakan proses penting dalam menyusui karena pada saat IMD terjadi kontak antara bayi dengan ibu, dimana bayi akan berusaha mencari puting ibu dan memulai menyusui. Bayi diletakan diatas dada atau perut ibu, secara alami bayi akan mencari sendiri sumber ASI kemudian menyusu. IMD ini direkomendasikan oleh WHO dilaksanakan selama satu jam pertama sejak bayi dilahirkan (Roesli, 2019). Sedangkan pemberian ASI diberikan kepada bayi sejak dilahirkan hingga berusia enam bulan, tanpa menambahkan dan/atau mengganti dengan makanan atau minuman lain kecuali obat, vitamin, dan mineral (Kementerian Kesehatan RI, 2017).

Hasil penelitian yang dilakukan oleh (Linawati \& Agustina, 2020) menunjukkan bahwa ada hubungan pemberian asi eksklusif dengan status gizi bayi 7-12 bulan di Wilayah Kerja Puskesmas Kalianda Lampung Selatan 2019. Penelitian yang 
JOURNAL OF PUBLIC HEALTH INOVATION,

VOL. 1 NO. 02, JUNI 2021

DOI: $10.34305 /$ iphi.v1i2.282

dilakukan oleh (Alim, 2019) menunjukkan bahwa terdapat hubungan antara pelaksanaan Inisiasi Menyusu Dini terhadap status gizi bayi dan terdapat pula hubungan pemberian ASI Eksklusif dengan status gizi bayi. Namun, berbeda dengan hasil penelitian yang dilakukan oleh (Ali, 2019) tidak terdapat hubungan Inisiasi Menyusu Dini terhadap status gizi anak di wilayah kerja Puskesmas Malaka Kelurahan Lapajung.

Berdasarkan studi pendahuluan yang dilakukan penulis dengan cara wawancara di Desa Bantaragung Kecamatan Sindangwangi Kabupaten Majalengka pada bulan April 2021 terhadap 10 bayi usia $7-12$ bulan, didapatkan hasil bahwa hanya 3 bayi (30\%) yang mendapatkan ASI pada satu jam pertama dan 4 bayi (40\%) yang mendapatkan ASI saja selama 6 bulan. Dari 10 bayi ditemukan 4 orang bayi yang menderita gizi kurang, sebagai akibat dari pemberian ASI yang tidak sesuai dengan waktu pemberian yang direkomendasikan yaitu pemberian ASI saja selama 6 bulan. Berdasarkan uraian tersebut penulis tertarik untuk melakukan penelitian dengan judul "Hubungan pelaksanaan IMD dan pemberian ASI Eksklusif dengan status gizi bayi di Desa
Ciptaan disebarluaskan di bawah Lisensi Creative Commons Atribusi-

NonKomersial-BerbagiSerupa 4.0

Internasional.

Bantaragung Kecamatan Sindangwangi Kabupaten Majalengka tahun 2021”.

\section{Metode Penelitian}

Penelitian menggunakan jenis peneltian analitik dengan pendekatan cross sectional. Populasi dalam penelitian ini adalah seluruh ibu yang mempunyai bayi usia (7-12 bulan) yang berdomisili di Desa Bantaragung Kecamatan Sindangwangi Kabupaten Majalengka berjumlah 40 orang responden. Sampel dalam penelitian ini adalah seluruh ibu yang mempunyai bayi 712 bulan di Desa Bantaragung Kecamatan Sindangwangi Kabupaten Majalengka. Adapun teknik pengambilan sampel yang digunakan yaitu total sampling. Variabel bebas dalam penelitian ini adalah pelaksanaan IMD dan pemberian ASI Eksklusif. Variabel terikat adalah status gizi bayi usia 7-12 bulan. Instrumen dalam penelitian ini adalah kuesioner, timbangan dan tabel status gizi WHO-NCHS. Kuesioner yang digunakan terdiri dari empat bagian, bagian pertama adalah tentang identitas responden, bagian kedua tentang pengukuran tinggi dan berat badan bayi, bagian ketiga untuk mengetahui apakah bayi diberikan ASI secara eksklusifi atau tidak dan bagian keempat untuk mengetahui apakah bayi mendapatkan IMD 
JOURNAL OF PUBLIC HEALTH INOVATION,

VOL. 1 NO. 02, JUNI 2021

DOI: $10.34305 /$ jphi.v1i2.282

atau tidak. Analisis datanya meliputi analisis univariat mengggunakan distribusi frekuensi dan analisis bivariat menggunakan uji chi square. Penelitian ini dilakukan di Desa Bantaragung Kecamatan
Ciptaan disebarluaskan di bawah Lisensi Creative Commons Atribusi-

Sindangwangi Kabupaten Majalengka. Waktu pelaksanaan penelitian dimulai pada bulan Mei-Juni tahun 2021.

\section{Hasil Penelitian}

1. Analisis Univariat

Tabel 1 Distribusi Frekuensi Status Gizi Bayi di Desa Bantaragung Kecamatan Sindangwangi Kabupaten Majalengka Tahun 2021

\begin{tabular}{ccc}
\hline Status Gizi & Frekuensi (f) & Presentase (\%) \\
\hline Gizi Buruk & 0 & 0 \\
Gizi Kurang & 10 & 25.0 \\
Gizi Baik & 26 & 65.0 \\
Gizi Lebih & 4 & 10.0 \\
\hline Total & $\mathbf{4 0}$ & $\mathbf{1 0 0}$ \\
\hline
\end{tabular}

Sumber : Hasil Penelitian Tahun 2021

Tabel 1 menunjukkan bahwa status gizi bayi usia 7-12 bulan di Desa Bantaragung Kecamatan Sindangwangi Kabupaten Majalengka tahun 2021 yang paling banyak yaitu gizi baik sebesar (65\%).

Tabel 2 Distribusi Frekuensi Pelaksanaan IMD pada Bayi di Desa Bantaragung Kecamatan Sindangwangi Kabupaten Majalengka Tahun 2021

\begin{tabular}{ccc}
\hline Pelaksanaan IMD & Frekuensi (f) & Presentase (\%) \\
\hline Tidak & 17 & 42.5 \\
Ya & 23 & 57.5 \\
\hline Total & $\mathbf{4 0}$ & $\mathbf{1 0 0}$
\end{tabular}

Sumber : Hasil Penelitian Tahun 2021

Berdasarkan tabel 2 pelaksanaan IMD pada bayi di Desa Bantaragung Kecamatan Sindangwangi Kabupaten Majalengka tahun 2021 kurang dari setengah (42,5\%) tidak melaksanakan IMD.

Tabel 3 Distribusi Frekuensi Pemberian ASI Eksklusif pada Bayi di Desa Bantaragung Kecamatan Sindangwangi Kabupaten Majalengka Tahun 2021 


\begin{tabular}{ccc}
\hline Pemberian ASI Eksklusif & Frekuensi (f) & Presentase (\%) \\
\hline Tidak eksklusif & 18 & 45.0 \\
Eksklusif & 22 & 55.0 \\
\hline Total & $\mathbf{4 0}$ & $\mathbf{1 0 0}$
\end{tabular}

Sumber : Hasil Penelitian Tahun 2021

Berdasarkan tabel 3 pemberian ASI Eksklusif pada bayi usia 7-12 bulan di Desa Bantaragung Kecamatan Sindangwangi Kabupaten Majalengka tahun 2021 kurang dari setengah (45,0\%) tidak diberi ASI secara eksklusif.

2. Analisis Bivariat

Tabel 4 Hubungan Pelaksanaan IMD terhadap Status Gizi Bayi di Desa Bantaragung Kecamatan Sindangwangi Kabupaten Majalengka Tahun 2021

\begin{tabular}{|c|c|c|c|c|c|c|c|c|c|}
\hline \multirow{3}{*}{ Pelaksanaan IMD } & \multicolumn{6}{|c|}{ Status Gizi } & \multirow{2}{*}{\multicolumn{2}{|c|}{ Total }} & \multirow{3}{*}{$P$-value } \\
\hline & \multicolumn{2}{|c|}{ Kurang } & \multicolumn{2}{|c|}{ Baik } & \multicolumn{2}{|c|}{ Lebih } & & & \\
\hline & $\mathrm{F}$ & $\%$ & $\mathrm{~F}$ & $\%$ & $\mathrm{~F}$ & $\%$ & $\mathrm{~F}$ & $\%$ & \\
\hline Tidak & 9 & 52,9 & 6 & 35,3 & 2 & 11,8 & 17 & 100,0 & \\
\hline $\mathrm{Ya}$ & 1 & 4,3 & 20 & 87,0 & 2 & 8,7 & 23 & 100,0 & 0,007 \\
\hline Jumlah & 10 & 25,0 & 26 & 65,0 & 4 & 10,0 & 40 & 100 & \\
\hline
\end{tabular}

Sumber : hasil penelitian 2021

Berdasarkan tabel 4 dapat diketahui bahwa dari 40 responden yang tidak melaksanakan IMD sebagian besar berstatus gizi kurang yaitu sebanyak 9 orang (52,9\%) dan responden yang melaksanakan IMD sebagian besar berstatus gizi baik sebanyak 20 orang (87,0\%). Hasil uji statistik Rank Spearman diperoleh nilai p-value sebesar 0,007 sehingga dapat dijelaskan bahwa terdapat hubungan pelaksanaan IMD terhadap status gizi bayi di Desa Bantaragung Kecamatan Sindangwangi Kabupaten Majalengka.

Tabel 5 Hubungan Pemberian ASI Eksklusif dengan status gizi Bayi di Desa Bantaragung Kecamatan Sindangwangi Kabupaten Majalengka Tahun 2021

\begin{tabular}{|c|c|c|c|c|c|c|c|c|c|}
\hline \multirow{3}{*}{$\begin{array}{c}\text { Pemberian ASI } \\
\text { Eksklusif }\end{array}$} & \multicolumn{6}{|c|}{ Status Gizi } & \multirow{2}{*}{\multicolumn{2}{|c|}{ Total }} & \multirow{3}{*}{ P-value } \\
\hline & \multicolumn{2}{|c|}{ Kurang } & \multicolumn{2}{|c|}{ Baik } & \multicolumn{2}{|c|}{ Lebih } & & & \\
\hline & $\mathrm{F}$ & $\%$ & $\mathrm{~F}$ & $\%$ & $\mathrm{~F}$ & $\%$ & $\mathrm{~F}$ & $\%$ & \\
\hline Tidak eksklusif & 9 & 50,0 & 6 & 33,3 & 3 & 16,7 & 18 & 100,0 & \\
\hline Eksklusif & 1 & 4,5 & 20 & 90,9 & 1 & 4,5 & 22 & 100,0 & 0,040 \\
\hline Jumlah & 10 & 25,0 & 26 & 65,0 & 4 & 10,0 & 40 & 100 & \\
\hline
\end{tabular}

Sumber : hasil penelitian 2021 
Berdasarkan tabel 5.5 dapat diketahui bahwa dari 40 responden yang tidak memberikan ASI secara eksklusif sebagian besar berstatus gizi kurang yaitu sebanyak 9 orang (50,0\%) dan responden yang melaksanakan IMD sebagian besar berstatus gizi baik sebanyak 20 orang (90,9\%). Hasil uji statistik Rank Spearman diperoleh nilai p-value sebesar 0,040 sehingga dapat dijelaskan bahwa terdapat hubungan pemberian ASI Eksklusif dengan status gizi bayi di Desa Bantaragung Kecamatan Sindangwangi Kabupaten Majalengka.

\section{Pembahasan}

1. Hubungan Pelaksanaan IMD terhadap Status Gizi Bayi di Desa Bantaragung Kecamatan Sindangwangi Kabupaten Majalengka

Hasil penelitian menunjukkan bahwa ada hubungan pelaksanaan inisiasi menyusu dini terhadap status gizi bayi di Desa Bantaragung Kecamatan Sindangwangi Kabupaten Majalengka dengan nilai $p$-value sebesar 0,007. Adanya hubungan hal ini dapat dikarenakan proses menyusu akan mempengaruhi pemberian ASI berikutnya, jika proses menyusu di awal bayi akan lahir berhasil maka proses pemberian ASI berikutnya pun akan berhasil sehingga bayi mendapatkan nutrisi cukup dan gizinya pun semakin baik.

Hasil penelitian ini sejalan dengan hasil penelitian (Alim, 2019) menunjukkan bahwa terdapat hubungan pelaksanaan Inisiasi Menyusui Dini terhadap status gizi bayi di Puskesmas Lamurukung. Namun berbeda dengan hasil penelitian (Ali, 2019) yang menyatakan bahwa tidak ada hubungan IMD dengan status gizi balita di Puskesmas Malaka Lalabata.

Hasil penelitian ini sejalan dengan teori yang mengatakan bahwa bayi yang mendapatkan IMD maka dia akan mendapatkan cairan kolostrum yang sangat penting dan bermanfaat bagi kekebalan tubuh bayi. Kolostrum ini akan memberikan perlindungan pada bayi, melancarkan pencernaan dan juga memberikan kekebalan terhadap infeksi atau penyakit. Cairan ini diberi nama the gift of life yang artinya dapat memberikan masa emas pada bayi (Roesli, 2019).

Menurut asumsi peneliti, pelaksanaan Inisiasi Menyusui Dini dapat mempengaruhi status gizi bayi, karena dengan Inisiasi Menyusui Dini bayi akan mendapatkan kolostrum yang kaya akan daya tahan tubuh. Maka dari itu untuk 
JOURNAL OF PUBLIC HEALTH INOVATION,

VOL. 1 NO. 02, JUNI 2021

DOI: $10.34305 /$ iphi.v1i2.282

meningkatkan pelaksanaan Inisiasi

Menyusui Dini yaitu dengan adanya kegiatan penyuluhan tentang pelaksanaan IMD pada ibu hamil yang akan melahirkan.

2. Hubungan Pemberian ASI Eksklusif dengan status gizi Bayi di Desa Bantaragung Kecamatan Sindangwangi Kabupaten Majalengka

Hasil penelitian menunjukkan bahwa terdapat hubungan pemberian ASI Eksklusif dengan status gizi bayi di Desa Bantaragung Kecamatan Sindangwangi Kabupaten Majalengka dengan nilai $p$-value sebesar 0,040. Hal ini dapat dikarenakan dengan pemberian ASI saja tanpa bahan makanan lain merupakan cara pemberian nutrisi dan gizi yang sangat tepat bayi karena ASI mengandung nutrisi pokok pada bayi sehingga pemberian ASI secara eksklusif dapat memenuhi gizi bayi.

Hasil penelitian ini sejalan dengan penelitian (Linawati \& Agustina, 2020) menunjukkan bahwa ada hubungan pemberian ASI dengan status gizi bayi di Wilayah Kerja Puskesmas Kalianda Lampung Selatan dengan $p$-value $=0,000$, $\mathrm{OR}=9,490$. Juga sejalan dengan penelitian (Parti, 2018), menunjukkan bahwa pemberian ASI Eksklusif ada hubungan yang signifikan dengan status gizi bayi.
Ciptaan disebarluaskan di bawah Lisensi Creative Commons AtribusiNonKomersial-BerbagiSerupa 4.0 Internasional
Hasil penelitian ini sejalan dengan teori (Roesli, 2019), yang menyatakan bahwa ASI adalah makanan pokok yang tepat untuk bayi, di samping murah, mudah untuk diberikan, higienis, dan sudah tersedia alami bagi bayi. ASI adalah satu satunya makanan pokok bayi tanpa bahan makanan lainnya sampai usia 6 bulan. ASI mengandung asupan gizi yang optimal dan tepat bagi bayi usia 0-6 bulan.

Hasil penelitian ini juga sejalan dengan teori yang menyatakan bahwa ASI memiliki semua unsur-unsur yang dibutuhkan oleh bayi, kecuali jika ibu megalami gangguan kesehatan. ASI lebih utama dan lebih baik dibanding dengan susu formula dan susu sapi. Selain itu, ASI mengandung trigliserida rantai sedang, asam lemak jenuh, dan kolesterol dalam jumlah yang cukup bagi kebutuhan bayi (Hardinsyah \& Supariasa, 2016).

Menurut asumsi peneliti, bahwa dengan pemberian ASI selama 6 bulan tanpa bahan makanan lain merupakan cara yang tepat dalam pemenuhan gizi bayi usia $0-6$ bulan. Hal ini karena ASI merupakan satu satunya makanan yang termasuk sempurna bagi bayi karena mengandung semua zat yang dibutuhkan oleh bayi.

\section{Kesimpulan}


JOURNAL OF PUBLIC HEALTH INOVATION,

VOL. 1 NO. 02, JUNI 2021

DOI: $10.34305 /$ iphi.v1i2.282

1. Sebagian besar bayi di Desa Bantaragung Kecamatan Sindangwangi Kabupaten Majalengka tahun 2021 adalah gizi baik sebesar $(65 \%)$.

2. Kurang dari setengah bayi di Desa Bantaragung Kecamatan Sindangwangi Kabupaten Majalengka tahun 2021 tidak mendapatkan IMD (42,5\%).

3. Kurang dari setengah bayi di Desa Bantaragung Kecamatan Sindangwangi Kabupaten Majalengka tahun 2021 tidak diberi ASI secara eksklusif (45,0\%).

4. Terdapat hubungan pelaksanaan IMD terhadap status gizi bayi di Desa Bantaragung Kecamatan Sindangwangi Kabupaten Majalengka dengan nilai $p$ value sebesar 0,007.

5. Terdapat hubungan pemberian ASI Eksklusif dengan status gizi bayi di Desa Bantaragung Kecamatan Sindangwangi Kabupaten Majalengka dengan nilai $p$ value sebesar 0,040 .

\section{Saran}

1. Untuk ibu dapat meningkatkan pengetahuan tentang IMD dan ASI Eksklusif dengan cara berkonsultasi kepada petugas kesehatan, membaca buku KIA dan majalah kesehatan sehingga dapat memperbaiki pemberian ASI pada bayinya.
Ciptaan disebarluaskan di bawah Lisensi Creative Commons Atribusi-

2. Tenaga kesehatan khususnya bidan yang berada di Desa Bantaragung Kecamatan Sindangwangi sebagai tenaga pelaksana kebidanan dan sumber informasi, agar dapat meningkatkan pelayanan kesehatan dengan sering mengadakan penyuluhan sehingga upaya program ASI Eksklusif selama 6 bulan tercapai dengan baik.

3. Bagi Institusi Pendidikan, diharapkan agar dapat memperbanyak kepustakaan yang berhubungan dengan status gizi bayi untuk mempermudah peneliti dalam penyusunan karya tulis ilmiah. Hasil penelitian ini dapat dijadikan acuan mahasiswa yang akan datang untuk penelitian lebih lanjut.

\section{Daftar Pustaka}

Ali, A. H. (2019). Hubungan Inisiasi Menyusui Dini (IMD) terhadap Status Gizi Bayi Dibawah Dua Tahun (BADUTA) di Puskesmas Malaka Kecamatan Lalabata Kabupaten Soppeng. ARTERI: Jurnal Ilmu Kesehatan, 1(1), 76-84. https://doi.org/10.37148/arteri.v1i1.26

Alim, N. (2019). Hubungan Pelaksanaan IMD dan Pemberian ASI Eksklusif dengan status gizi Bayi di Puskesmas Lamurukung. Celebes Health Journal, 1(2), 2685-1970. Retrieved from http://journal.lldikti9.id/CPHJ/indexD OI:https://doi.org/ 
JOURNAL OF PUBLIC HEALTH INOVATION,

VOL. 1 NO. 02, JUNI 2021

DOI: $10.34305 /$ iphi.v1i2.282

Almatsier, S. (2016). Prinsip Ilmu Gizi Dasar. Jakarta: PT. Gramedia Pustaka Utama.

Dewi, V. N. (2017). Asuhan Neonatus Bayi dan Anak Balita. Jakarta: PT. Rineka Cipta.

Dinas Kesehatan Kabupaten Majalengka. (2020). Profil Kesehatan Kabupaten Majalengka Tahun 2019. Majalengka: Dinas Kesehatan Kabupaten Majalengka.

Hardinsyah, \& Supariasa, I. D. N. (2016). Ilmu Gizi Teori \& Aplikasi. In Buku Kedokteran ECG.

Indrayani, \& Moudy, D. (2016). Asuhan Persalinan dan Bayi Baru Lahir. Surabaya: CV Trans Info Media.

Kementerian Kesehatan RI. (2017). Pedoman Penyelenggaraan Pekan ASI Sedunia. Jakarta: Kementerian Kesehatan RI.

Kementerian Kesehatan RI. (2020). Profil Kesehatan Indonesia Tahun 2019. Jakarta: Kementrian Kesehatan RI.

Kementrian Kesehatan RI. (2018). Situasi Balita Pendek. In Kementerian Kesehatan RI.
Ciptaan disebarluaskan di bawah Lisensi Creative Commons Atribusi-

NonKomersial-BerbagiSerupa 4.0

Internasional.

Linawati, \& Agustina, H. (2020). Hubungan Pemberian Asi Eksklusif Dengan Status Gizi Bayi 7-12 Bulan Di Wilayah Kerja Puskesmas Kalianda Lampung Selatan. Manuju: Malahayati Nursing Journal, P-Issn: 2655-2728 EIssn: 2655-4712, 2(1), 140-150.

Notoatmodjo, S. (2018). Metodologi Penelitian Kesehatan. Jakarta: PT Rineka Cipta.

Parti, Stik. (2018). Hubungan Pemberian ASI Eksklusif dengan Status Gizi Bayi Usia 6-12 Bulan. Hubungan Pemberian ASI Eksklusif Dengan Status Gizi Bayi Usia 6-12 Bulan, (2).

Rini, S. (2016). Panduan Asuhan Nifas dan Evidence Based Practice. Jakarta: CV. Budi Utama.

Roesli, U. (2019). Mengenal Asi Ekslusif. Trubus Agriwidya.

Sugiyono. (2017). Metode Penelitian Kuantitatif, Kualitatif, dan $R \& D$. Bandung: Alphabeta.

Supariasa, I. D. N. (2018). Pendidikan dan Konsultasi Gizi. Jakarta: Buku Kedokteran ECG.

Tuti, M. (2019). 1000 Hari Pertama Kehidupan. Yogyakarta: CV Budi Utama. 